\title{
Effect of preloaded micropile on the foundation underpinning by centrifuge experiments
}

\author{
C. WANG* + t and J.-T. HAN§
}

\begin{abstract}
Micropiles (MP) are widely used for underpinning existing buildings that are being vertically extended. They can be preloaded after installation, whereby partial loads are transferred from existing piles (EP) to the MP to prevent the EP from being overloaded during the vertical extension work. This paper evaluates the effect of preloading on the load transfer from the EP to a MP and the load-sharing mechanism among pile groups subjected to subsequent vertical loading. This study presents a series of centrifuge experiments conducted on a $2 \times 2$ pile foundation underpinned with a MP. Before the foundation was subjected to vertical loading, a preload of $10 \%$ of the MP's bearing capacity was applied to its head. The experimental results show that the preloading facilitates the transfer of partial loads from EP to the MP, with the load-transfer efficiency being more than $90 \%$. During subsequent loading tests, the application of preloading made the load-sharing ratio of the MP about $20 \%$ higher than that in a comparable case without preloading.
\end{abstract}

KEYWORDS: bearing capacity; centrifuge modelling; piles \& piling

Published with permission by the ICE under the CC-BY 4.0 license. (http://creativecommons.org/licenses/by/4.0/)

\author{
NOTATION \\ $D_{\mathrm{p}}$ diameter of a pile \\ $D_{\mathrm{r}} \quad$ relative density of soil \\ $K_{\mathrm{EP}} \quad$ axial stiffness of the existing pile \\ $K_{\mathrm{MP}}$ axial stiffness of the micropile \\ $Q$ load applied to the foundation \\ $Q_{\mathrm{U}}$ ultimate bearing capacity of the foundation \\ settlement of a pile \\ $\sigma_{\mathrm{c}} \quad$ uniaxial compressive strength of rock
}

\section{INTRODUCTION}

Remodelling existing buildings by vertical extension can aid the redevelopment of inner-city sites requiring taller buildings. As additional stories are applied on existing foundations, the capacity of the existing piles (EP) might be insufficient to support the new structure. Underpinning existing foundations with micropiles (MP) can enhance their capacity (Bruce, 1988; Juran et al., 1999; Lizzi, 1982). However, key geotechnical concerns remain unresolved regarding the behaviour of the mixture of existing and underpinning piles when supporting the additional loads of an extended structure. Some studies have explored the interactions among the old and new piles and the soil, and the influence of new piles on existing foundations when existing foundations are reused (Makarchian \& Poulos, 1996; Tsubakihara \& Yamashita, 2005; Han \& Ye, 2006; Tsukada et al., 2006; Begaj \& McNamara, 2011; Leung et al., 2011; Tamura et al., 2012; Kim et al., 2019).

Manuscript received 14 February 2020; first decision 22 December 2020; accepted 1 February 2021.

Published online at www.geotechniqueletters.com on 9 February 2021.

*Traffic and Municipal Engineering Institute, POWERCHINA Huadong Engineering Corporation Limited, Hangzhou, China.

$\dagger$ Zhejiang Engineering Research Center on Smart Rail Transportation, Hangzhou, China.

$\$$ Civil \& Environmental Engineering, University of Science and Technology, Daejeon, Korea.

\$Department of Infrastructure Safety Research, Korea Institute of Civil Engineering and Building Technology, Gyeonggi, Korea.
It is considered that the additional loads are shared by the newly installed MP and the EP that had been previously subjected to their working loads from the existing structure. As a result, the allowable bearing capacity of the EP could be exceeded. Some studies have demonstrated that the preloading of piles not only minimises the settlement of foundations, but also increases the stiffness and capacity of the piles. Some researchers have investigated the preloading effect on the improving single pile load-settlement responses (Brand, 2005; Begaj \& McNamara, 2011; Sheil, 2017). Wang et al. (2018, 2020) proposed a method of preloading for underpinned foundations, whereby MP are preloaded through a special apparatus prior to connect them to the existing foundation during installation. The method aimed to transfer partial loads from the EP to the MP through action and reaction theory, and to generate displacements of the MP in order to minimise structural movements and improve load-bearing capacity. Preliminary centrifuge tests have verified the feasibility of preloading to transfer loads from EP to MP in sand, but they failed to evaluate the stability and load sharing between the EP and the MP during the subsequent additional loading due to the high level of preloading (Wang et al., 2020). Therefore, this study consisted of centrifuge tests with the aim of exploring the effect of a proper preloading level for the MP on the stability and load sharing of the underpinned foundation.

\section{CENTRIFUGE MODELLING OF PILE FOUNDATIONS}

Four sets of experiments were conducted under an acceleration of $23 \boldsymbol{g}$ (Kim et al., 2013). Figure 1 and Table 1 present the considered test cases and their arrangements of EP and MP, plans of the test set-up, soil profiles, pile models and instrumentation. The complicated whole loading stages (i.e. initial loading to existing foundation, preloading and additional loading to underpinned foundation) was difficult to be achieved in a spinning centrifuge, preloading and additional loading sequences were considered for the main objectives of evaluation of preloading method for its effects on the load transfer between EP and the MP, and load sharing among them during subsequent loading tests. The 


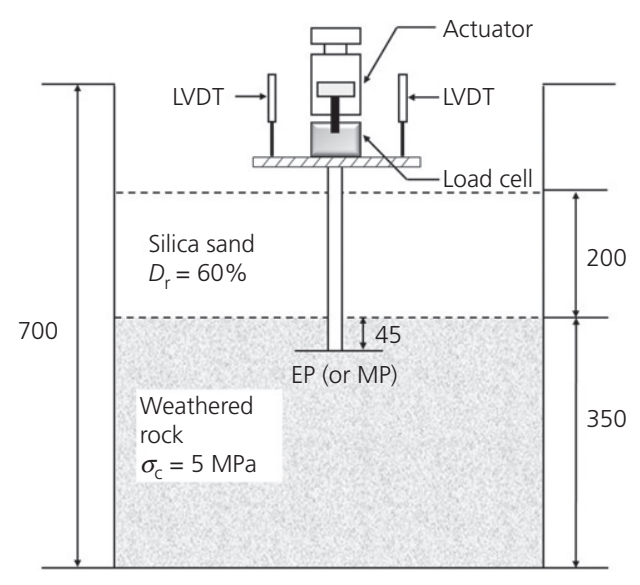

(a)

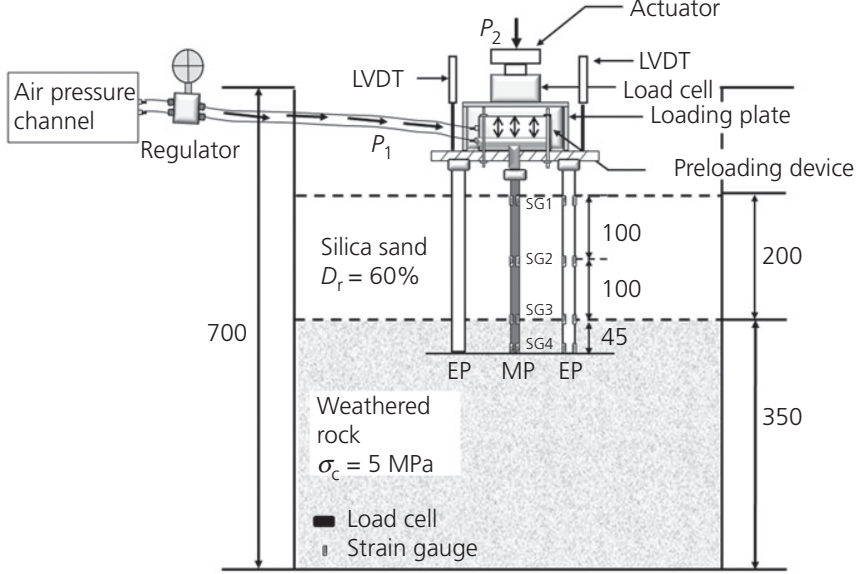

(b)

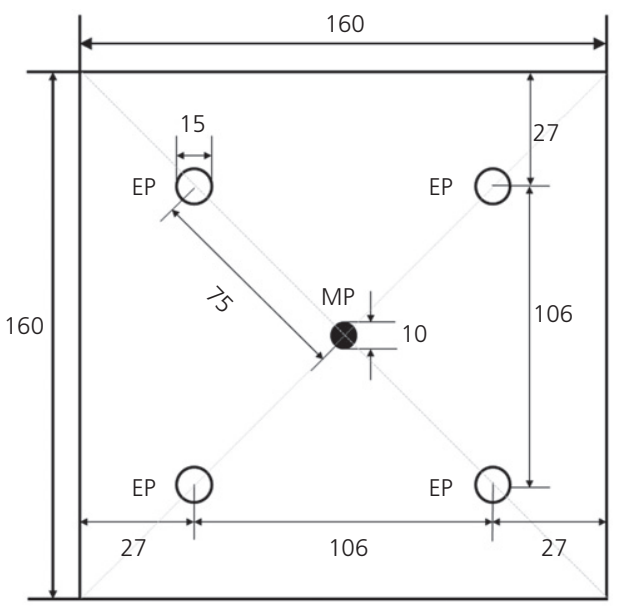

(c)

Fig. 1. The experimental tests (in model scale; unit: $\mathrm{mm}$ ). (a) Set-up of single pile loading test (case 1 or 2); (b) set-up of pile group loading test (case 3, step 1: preloading to MP by preloading device; step 2: loading to the pile group by the actuator); (c) plan view of the pile group. LVDT, linear variable differential transformer

Table 1. Details of experimental cases

\begin{tabular}{|c|c|c|c|}
\hline Case & Pile & Loading stage & Description \\
\hline $\begin{array}{l}1 \\
2 \\
3 \text { preloading } \\
4 \text { no preloading }\end{array}$ & $\begin{array}{l}\mathrm{EP} \\
\mathrm{MP} \\
4 \mathrm{EP}+1 \mathrm{MP} \\
4 \mathrm{EP}+1 \mathrm{MP}\end{array}$ & $\begin{array}{l}\text { Vertical loading to single pile until failure } \\
\text { Step 1: preloading } P_{1} \text { to MP } \\
\text { Step 2: vertical loading } P_{2} \text { to pile group } \\
\text { Vertical loading to pile group }\end{array}$ & $\begin{array}{l}\text { Single pile } \\
\text { Pile group } \\
\left.\quad \text { (pile spacing: } 5 D_{\mathrm{EP}}{ }^{*}\right)\end{array}$ \\
\hline
\end{tabular}

*Diameter of EP.

Table 2. Dimensions of prototype and model piles

\begin{tabular}{l|c|c|c|r|r}
\hline \multirow{2}{*}{ Pile type } & \multicolumn{2}{|c|}{ PC pile: EP } & \multicolumn{3}{c}{ MP } \\
\cline { 2 - 6 } & Prototype & Model & \multicolumn{2}{|c}{ Prototype } & Model \\
\hline Material & Concrete & Aluminium & Grout & Steel bar & Aluminium \\
\hline Young's modulus: GPa & 40 & 69 & 37 & 210 & 69 \\
Diameter: mm & 350 & 15 & 230 & 50 & 10 \\
$\quad$ Outer & 65 & 13 & - & & 6 \\
$\quad$ Inner & 5635 & 245 & 5635 & & 45 \\
Length: mm & 1000 & 45 & 1000 & & 45 \\
Socket length: mm & & & & & \\
\hline
\end{tabular}


self-weight (prototype $360 \mathrm{kN}$ ) of the plate was simulated as initial loading to piles. The scaling law derived the dimensions of the prototype and model piles (Table 2) with a scaling ratio of 23 (Wood, 2014).

Preloading used a special apparatus to impose loads at the head of the MP, prior to applying loads to the underpinned foundation. Wang et al. (2020) described the details of the preloading mechanism. In this study, preloading in the centrifuge tests was achieved by pneumatic pressure injected into the preloading device and controlled by a pressure regulator. The preload level should be within the linear elastic range of the load-settlement curve for the MP (Wang et al., 2020).

Cases 3 and 4 included load cells installed on the pile head to measure the load carried by each pile under preloading and subsequent additional loading. Four pairs of strain gauges were attached to both sides of one existing pile and the MP to measure the load transfer along the piles.

Two layers, sand and weak rock were set to model the ground. The sand was air-pluviated to prepare an upper layer with relative density, $D_{\mathrm{r}}=60 \%$. The weak rock stratum comprised gypsum, silica sand and water (Leung \& Ko, 1993; Dykeman \& Valsangkar, 1996; Seo et al., 2018) mixed in a $1: 2 \cdot 3: 1$ ratio to achieve a desired compressive strength of $5 \mathrm{MPa}$. Figure 2 presents the uniaxial compressive strength of the prepared lab-scale rock samples with respect to curing time. The tests were performed using artificial rock cured for 12 days.

\section{RESULTS}

\section{Single pile loading test}

Figure 3 plots the load-settlement responses for test single piles. The bearing capacities of the existing pile and MP were estimated as 400 and $760 \mathrm{kN}$, respectively, based on the $\mathrm{P}-\mathrm{S}$ criterion. The axial stiffness of the existing pile obtained from the initial slope of the load-settlement response was $65 \mathrm{kN} / \mathrm{mm}$, which is 1.5 times that of the MP $(43 \mathrm{kN} / \mathrm{mm})$. The bearing capacity of the MP will be used as a reference for the determination of the preload value in subsequent preloading tests.

\section{Pile group loading tests}

Figure 4 plots the load carried by each pile caused by the self-weight of the plate during spinning from $1 \mathrm{~g}$ to $23 \mathrm{~g}$. All piles are under compressive behaviour and the carried load

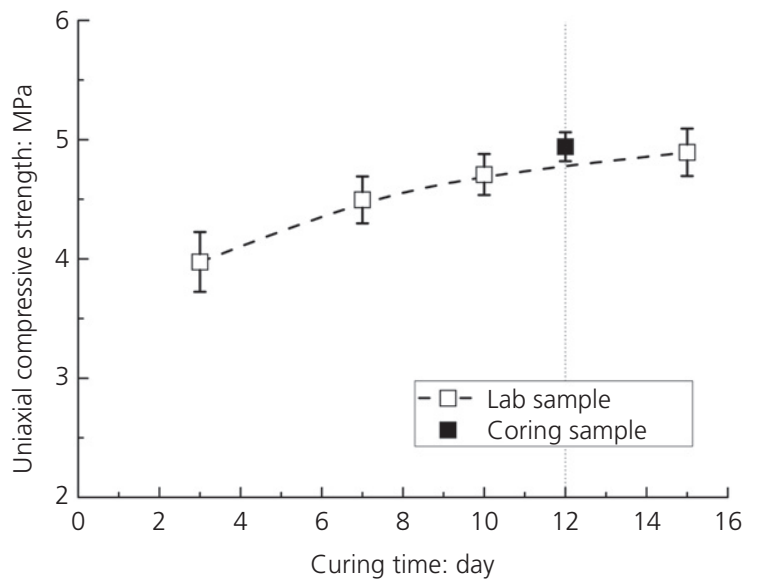

Fig. 2. Uniaxial compressive strength of artificial weak rock with respect to curing duration (lab sample: lab-scale sample prepared in the laboratory before centrifuge tests; Coring sample: drilled from rock layer after centrifuge tests)

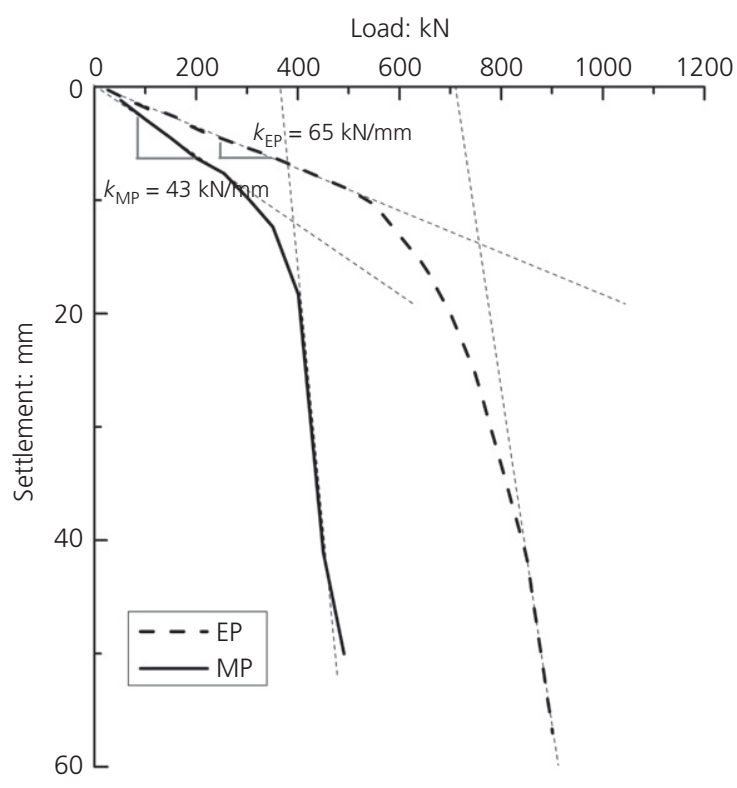

Fig. 3. Load-settlement curves of single piles

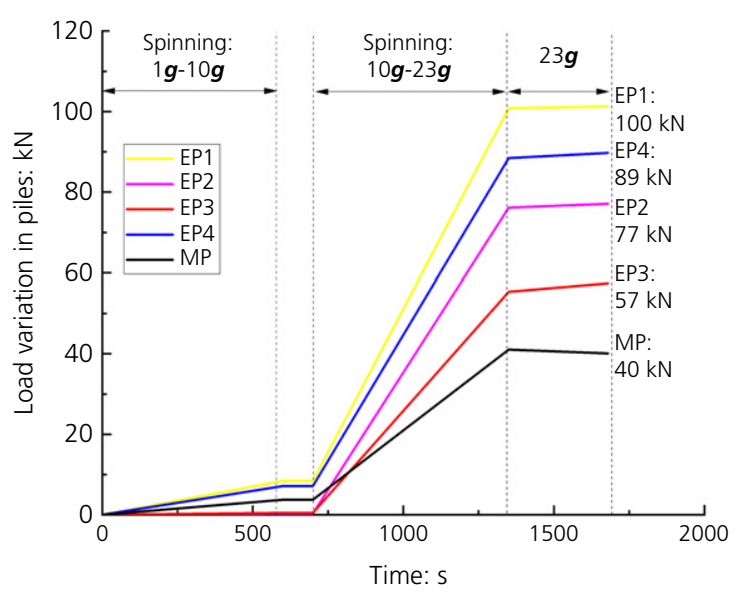

Fig. 4. Load variation in piles under initial loading during spinning from $1 \boldsymbol{g}$ to $23 \boldsymbol{g}$

by each pile is in the linear zone of the load-settlement curve, which shows insignificant influence on the load sharing. For the evaluation of load variation in piles during preloading and additional loading, all data presented in this study were zero calibrated after spinning.

Load transfer during preloading. A preload of $40 \mathrm{kN}$ based on the $10 \%$ ultimate capacity of the MP was imposed in three stages to the MP as shown in Fig. 5. Positive and negative values obtained by the load cells on the piles' heads indicate loading and unloading behaviour, respectively. The figure shows that with increasing pressure on the MP, the load on each existing pile decreased. The loads on all piles remained constant when injection stopped.

Figure 6 shows load transfer among the EP and MP with respect to preloading level. The total load reduction on the EP increased linearly with increasing preload on the MP. The slope of 0.92 indicates that the load-transfer efficiency from the EP to the underpinning pile was $>90 \%$. Due to the complex interaction of existing pile-soil-MP and connection system, the approximately $10 \%$ load loss was reasonably assumed to be caused by friction of pile-soil interface and 


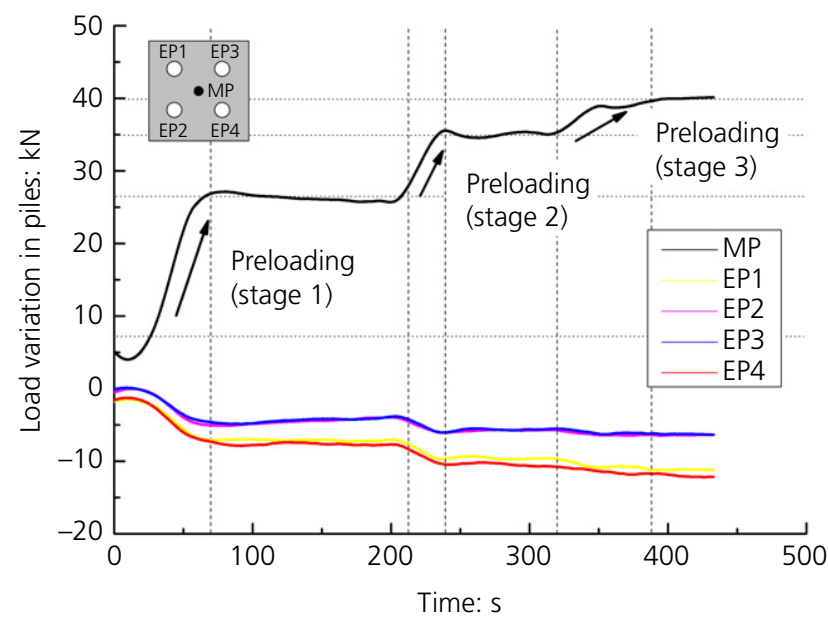

Fig. 5. Variation of loading on piles during MP preloading (positive values: loading; negative values: unloading)

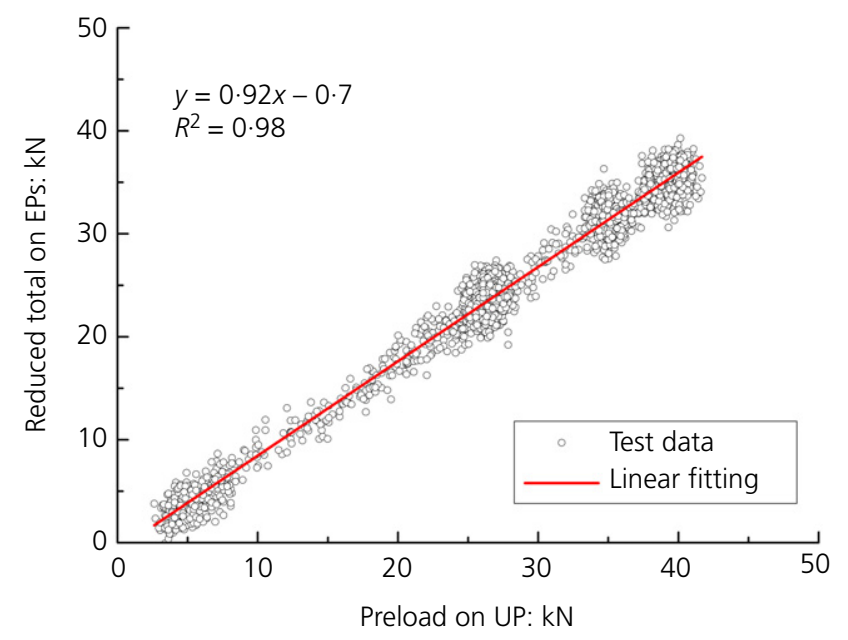

Fig. 6. Load-transfer efficiency of the preloading method between EP to the MP

mechanical friction at the connection of the plate and preloading device (Khazaei et al., 2006; Hong, 2017).

Figure 7 gives information on the load distribution measured along the piles during preloading using strain gauges. It shows that axial load along the MP increased with increasing preload and decreased with increasing soil depth. In contrast, preloading the MP led to unloading behaviour in the $\mathrm{EP}$, indicating the mobilisation of shaft resistance along them to resist their being pulled out.

\section{Load sharing of underpinned foundation under loading.}

After preloading, loading tests on the underpinned foundation were conducted to evaluate the influence of preloading on load sharing among the piles under loading. The load carried on piles were obtained from load cells, and the results were not affected by the load loss during preloading.

Figure 8 plots load-settlement curves for pile groups with and without preloading. The bearing capacity of these pile groups with and without preloading is estimated to be 3980 and $3700 \mathrm{kN}$, respectively, which are close to the sum of the capacities of the individual piles. The similar behaviour in both cases indicates that a proper value of preloading (which is set to be in the elastic range of the load-settlement curve of the MP) had little influence on the stability of the foundation during loading.

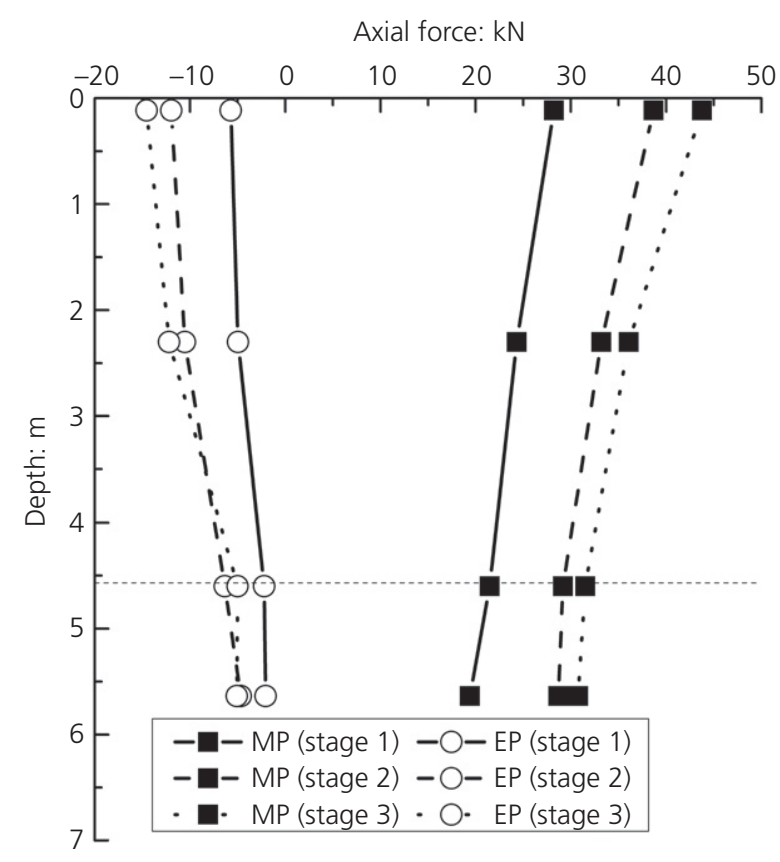

Fig. 7. Load distribution along the pile shaft due to MP preloading

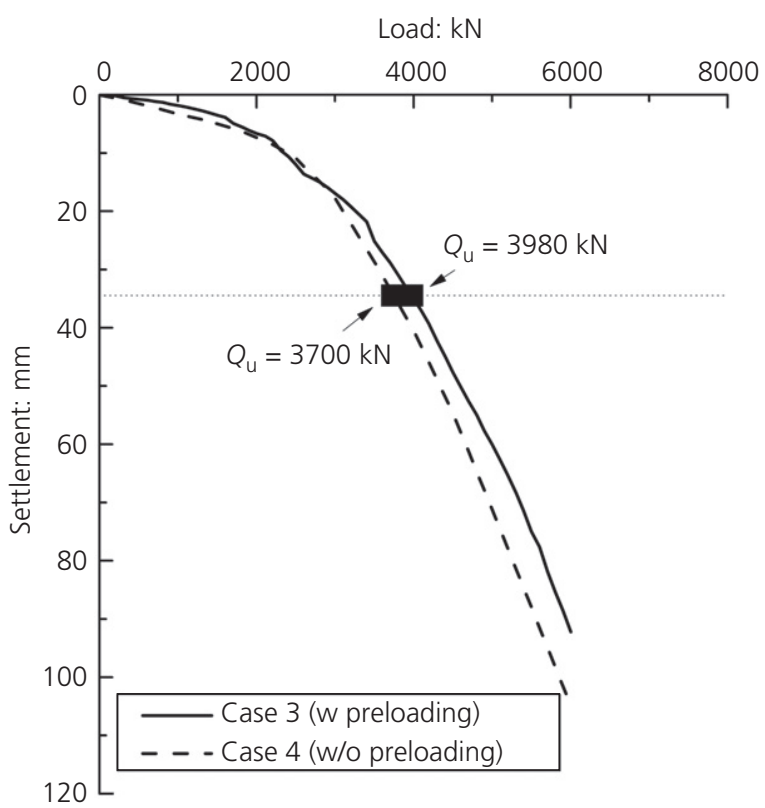

Fig. 8. Load-settlement behaviour of group pile subjected to additional loading

Figure 9 shows the variation of load sharing by each pile in the underpinned foundation under loading. The loads on all piles increased with the increasing load applied to the plate. In case 3, as a result of prior load transfer between the EP and MP by preloading, the MP started to carry loads at a positive value of $40 \mathrm{kN}$, while the EP started to carry the load at a negative value. The load-carrying capacity of an existing pile was higher than that of the MP due to its greater stiffness. This is consistent with results of previous studies (Kim et al., 2019; Wang et al., 2019). However, in case 3 at low loading levels of $<2500 \mathrm{kN}$, increasing the load applied to the plate caused the MP to carry little load, the load on EP4 to decrease, and the load on EP1 to increase sharply. This eccentricity may be attributed to some errors in the experimental set-up, such as the disturbance of the soil or the incorrect installation of the 


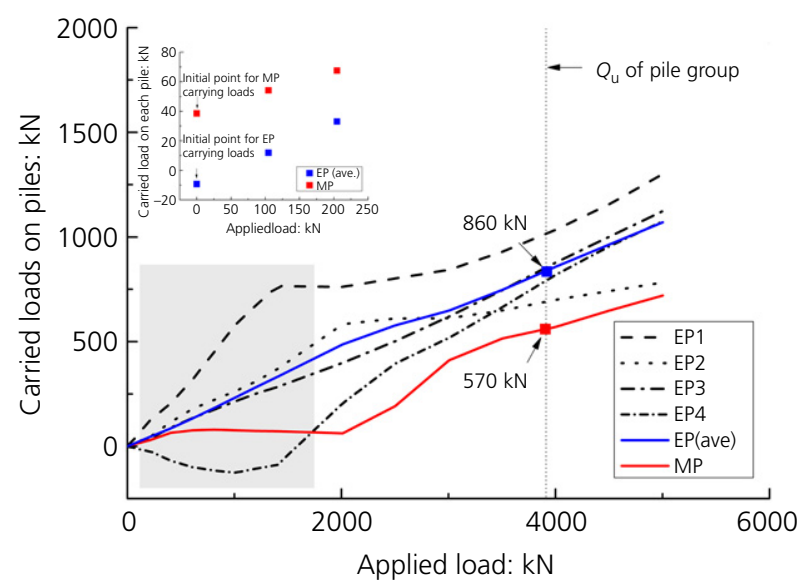

(a)

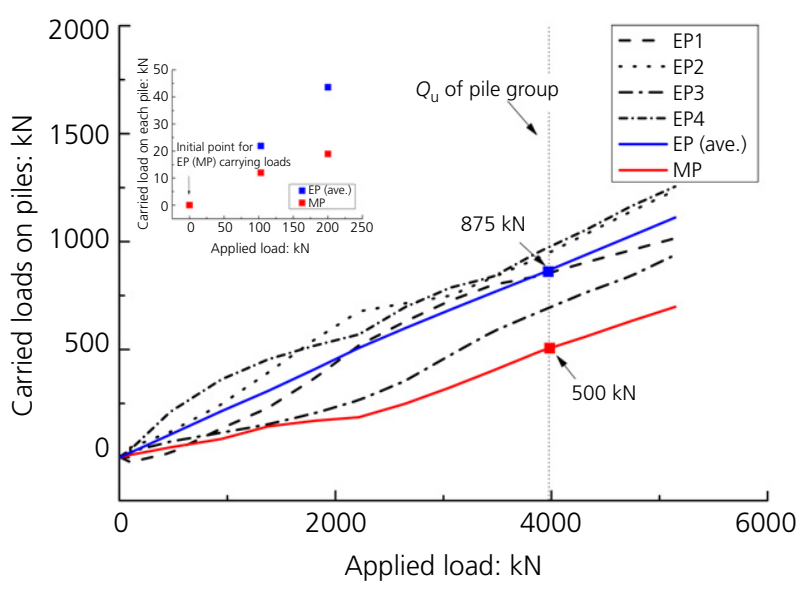

(b)

Fig. 9. Comparison of load sharing among piles subjected to additional loading. (a) Case 3: with preloading; (b) case 4: without preloading

Axial force: $\mathrm{kN}$

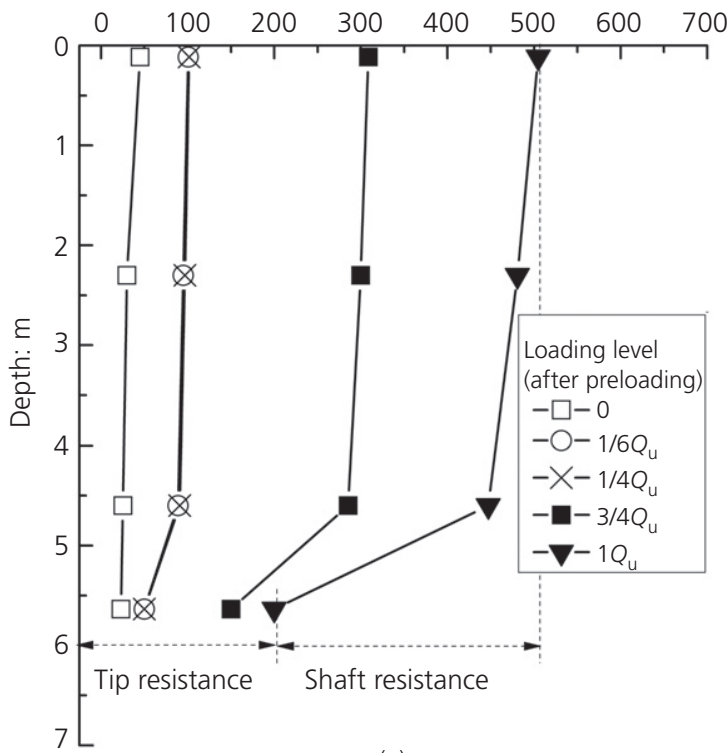

(a)

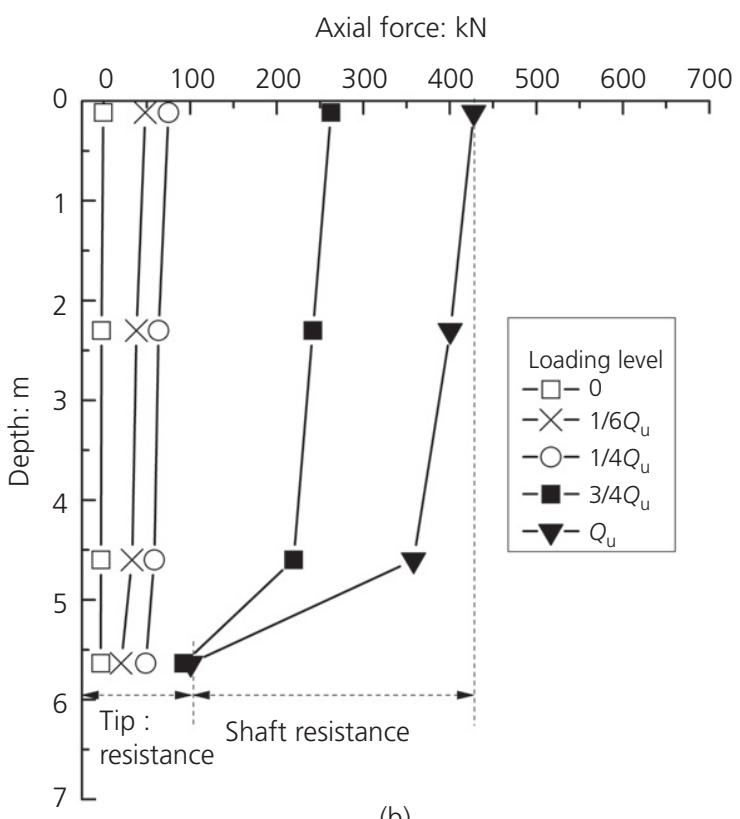

(b)

Fig. 10. Load distribution along the MP shaft in a pile group subjected to additional loading. ( $Q_{\mathrm{u}}$ : ultimate capacity of the pile group). (a) Case 3: with preloading; (b) case 4: without preloading

piles. Subsequently, after the piles reached a stable state, the load-carrying capacity of a pile when subjected to vertical loading greatly depended on its stiffness.

Figure 10 presents the load distribution on the MP during vertical load tests. The load on the pile in each case tended to increase with increasing applied load and to decrease with depth. At higher loading levels exceeding the ultimate capacity of the pile group, the axial load along the MP still increased as the applied load increased, despite the carried load exceeding the estimated bearing capacity $(400 \mathrm{kN})$. This reveals that the shaft and tip resistance of a MP in the pile group were greater than that of a single MP, thus demonstrating a contribution of the group pile effect. Moreover, comparison of Figs 10(a) and 10(b) shows that the application of preloading to the MP mobilised higher tip resistance than that which occurred without preloading under the same loading level.

The level of preload applied to the MP plays an important role during its subsequent sharing of loads (Wang et al., 2020). Table 3 lists the effects of preloading on the load
Table 3. Load sharing among piles under additional loading

\begin{tabular}{|c|c|c|c|c|c|}
\hline \multirow[t]{2}{*}{ Pile } & \multirow[t]{2}{*}{ Preloading } & \multicolumn{4}{|c|}{ Applied load, $Q: \mathrm{kN}$} \\
\hline & & 500 & $1500^{*}$ & 3000 & 3500 \\
\hline \multicolumn{6}{|c|}{ Load sharing: $\mathrm{kN}$} \\
\hline \multirow[t]{2}{*}{$\mathrm{EP} \times 4$} & With & 384 & 1392 & 2556 & 2896 \\
\hline & Without & 460 & 1348 & 2688 & 3089 \\
\hline \multirow[t]{2}{*}{ MP } & With & 114 & 111 & 451 & 540 \\
\hline & Without & 48 & 157 & 316 & 410 \\
\hline \multicolumn{6}{|c|}{ Load sharing ratio: $\%$} \\
\hline \multirow[t]{2}{*}{$\mathrm{EP} \times 4$} & With & $84 \cdot 4$ & $94 \cdot 8$ & 86 & $85 \cdot 2$ \\
\hline & Without & $90 \cdot 4$ & $89 \cdot 6$ & $89 \cdot 6$ & $88 \cdot 3$ \\
\hline \multirow[t]{2}{*}{ MP } & With & $14 \cdot 7$ & $4 \cdot 7$ & $13 \cdot 6$ & $14 \cdot 5$ \\
\hline & Without & $9 \cdot 5$ & $10 \cdot 4$ & $10 \cdot 5$ & $11 \cdot 7$ \\
\hline
\end{tabular}

*In this loading level, the eccentricity of piles led to the load sharing of MP smaller than that in other loading levels as explained in Fig. 8. 
sharing among piles at specific loading levels. The loadsharing ratio of one existing pile is 1.5 times that of the MP due to its higher stiffness. Comparing cases 3 and 4 shows that preloading increased the load-sharing capacity of the MP by about $20 \%$ relative to that achieved without preloading. This can be accounted for considering that preloading generated settlement of the MP, thus minimising or eliminating any structural movement during subsequent loading. This helped to improve load-sharing capacity of the MP and create a more stable foundation for the structure.

\section{CONCLUSIONS}

A series of centrifuge experiments investigated the effect of preloading on the performance of foundation underpinning in the terms of load transfer and load sharing among the EP and the underpinning MP before and after loading. The conclusions are as follows.

(a) Preloading the MP prior to applying loading to the foundation transferred loads carried by the EP to the MP, thereby preventing overloading of the existing foundation under subsequent loading. The load-transfer efficiency achieved by preloading was more than $90 \%$.

(b) When an underpinned foundation was subjected to loading, a proper level of preload applied to the MP $(10 \%$ of its ultimate capacity in this study) showed little influence on the stability of the underpinned foundation. Furthermore, the load-sharing capacity of the preloaded MP was $20 \%$ higher than that of one without preloading. This demonstrates that preloading also increases MP underpinning performance.

(c) For optimal design of underpinning with preloaded MP, the level of preload applied to the MP should not exceed the linear zone of its load-settlement response. Considering the load loss in the preloading device, the applied preload is suggested to be $10 \%$ higher than the design load.

Some limitations including loading sequences and eccentric loading existed, whereas it is believed that the results can provide a reference for the design of foundation underpinning.

\section{ACKNOWLEDGEMENTS}

This research was funded by a grant (21RERP-B099826-07) from the Residential Environment Research Program (RERP), which is funded by the Ministry of Land, Infrastructure and Transport of the Korean government.

\section{REFERENCES}

Begaj, L. \& McNamara, A. M. (2011). Centrifuge model testing for pile foundation reuse. Int. J. Phys. Model. Geotech. 11, No. 4, $166-177$.

Brand, H. (2005). Cyclic preloading of piles to minimize (differential) settlements of high-rise buildings. Slovak J. Civ. Engng (eigneladen) 3, 1-12.
Bruce, D. A. (1988). Aspects of minipiling practice in the United States. Ground Engng 21, No. 8, 20-33.

Dykeman, P. \& Valsangkar, A. J. (1996). Model studies of socketed caissons in soft rock. Can. Geotech. J. 33, No. 5, 747-759.

Han, J. \& Ye, S. L. (2006). A field study on the behavior of micropiles in clay under compression or tension. Can. Geotech. J. 43, No. 1, 19-29.

Hong, S. (2017). Effect of prestress levels and jack methods on friction losses in curved prestressed tendons. Appl. Sci. 7, No. 8, 824.

Juran, I., Bruce, D. A., Dimillio, A. \& Benslimane, A. (1999). Micropiles: the state of practice. Proc. Inst. Civ. Engng - Ground Improvement 3, No. 3, 89-110.

Khazaei, S., Wu, W., Shimada, H. \& Matsui, K. (2006). Effect of lubrication strength on efficiency of slurry pipe jacking. In Underground construction and ground movement (eds H. Zhu, F. Zhang, C. T. Chin and D. Zhang), pp. 170-177. Reston, VA, USA: ASCE.

Kim, D. S., Kim, N. R., Choo, Y. W. \& Cho, G. C. (2013). A newly developed state-of-the-art geotechnical centrifuge in Korea. Korean Soc. Civ. Engng 17, No. 1, 77-84.

Kim, D. H., Kim, J. H. \& Jeong, S. S. (2019). Estimation of axial stiffness on existing and reinforcing piles in vertical extension remodeled buildings. Engng Struct. 199, 109466.

Leung, C. R. \& Ko, H. Y. (1993). Centrifuge model study of piles socketed in soft rock. Soils Found. 33, No. 3, 80-91.

Leung, Y. F., Soga, K. \& Klar, A. (2011). Multi-objective foundation optimization and its application to pile reuse. In Geo-frontiers 2011: advances in geotechnical engineering (eds J. Han and D. E. Alzamora), pp. 75-84. Reston, VA, USA: ASCE.

Lizzi, F. (1982). The static restoration of monuments: basic criteria, case histories: strengthening of buildings damaged by earthquakes. Genova, Italy: Sagep.

Makarchian, M. \& Poulos, H. G. (1996). Simplified method for design of underpinning piles. J. Geotech. Engng 122, No. 9, 745-751.

Seo, S., Park, J., Lee, S. \& Chung, M. (2018). Analysis of pull-out behavior of tunnel-type anchorage for suspended bridge using 2-D model tests and numerical analysis. J. Korean Geotech. Soc. 34, No. 10, 61-74.

Sheil, B. (2017). Numerical simulations of the reuse of piled raft foundations in clay. Acta Geotech. 12, No. 5, 1047-1059.

Tamura, S., Higuchi, Y., Hayashi, Y. \& Yamzasaki, M. (2012). Centrifuge studies on the effects of existing piles on the end resistance and shaft friction of a new pile. Soils Found. 52, No. 6, 1062-1072.

Tsubakihara, Y. \& Yamashita, K. (2005). Reuse of existing piles in building reconstruction and its environmental effects. The 2005 world sustainable building conference, Tokyo, pp. 2676-2682.

Tsukada, Y., Miura, K., Tsubokawa, Y., Otani, Y. \& You, G. L. (2006). Mechanism of bearing capacity of spread footings reinforced with micropiles. Soils Found. 46, No. 3, 367-376.

Wang, C. C., Han, J. T., Ha, I. S. \& Kim, S. J. (2018). Study on the effectiveness of preloading method on reinforcement of the pile foundation by 3D FEM analysis. J. Korean Geotech. Soc. 34, No. $1,47-57$.

Wang, C. C., Han, J. T. \& Jang, Y. E. (2019). Experimental investigation of micropile stiffness affecting the underpinning of an existing foundation. Appl. Sci. 9, No. 12, 2495.

Wang, C. C., Han, J. T. \& Jang, Y. E. (2020). Investigation of effectiveness of preloading method for existing foundation underpinning by centrifuge tests. In Geotechnics for sustainable infrastructure development, Hanoi, pp. 61-67. Singapore: Springer.

Wood, D. M. (2014). Geotechnical modelling. Boca Raton, FL, USA: CRC Press.

\section{HOW CAN YOU CONTRIBUTE?}

To discuss this paper, please submit up to 500 words to the editor at journals@ice.org.uk. Your contribution will be forwarded to the author(s) for a reply and, if considered appropriate by the editorial board, it will be published as a discussion in a future issue of the journal. 